\title{
Experiencing a traumatic spinal cord injury-Analysis on the view of the theory of Watson's transpersonal caring
}

\author{
Zuila Maria de Figueirêdo Carvalho ${ }^{1,2,3,4}$, Juan Jose Tirado Darder ${ }^{4,5}$, Priscila Alencar Mendes Reis ${ }^{2,4}$, \\ Samira Rocha Magalhães, ${ }^{2,4}$, Samia Jardelle Costa de Freitas Maniva ${ }^{2,4,6}$ \\ ${ }^{1}$ New University of Lisbon, Lisbon, Portugal \\ ${ }^{2}$ Federal University of Ceará, Fortaleza, Brazil \\ ${ }^{3}$ The National Council for Scientific and Technological Development (CNPq), Brasilia, Brazil \\ ${ }^{4}$ Nupen/DENF/FFOE/UFC, Fortaleza, Brazil \\ ${ }^{5}$ School of Nursing, Cardenal Herrera University, Valencia, Spain \\ ${ }^{6}$ Clinical Care Health State University of Ceará, Fortaleza, Brazil \\ Email: zmfca@fortalnet.com.br, juanjo.tirado@gmail.com, prialencarmendes@hotmail.com, samira_magalhaes@hotmail.com, \\ samia.jardelle@gmail.com
}

Received 1 May 2013; revised 10 June 2013; accepted 25 June 2013

Copyright (c) 2013 Zuila Maria de Figueirêdo Carvalho et al. This is an open access article distributed under the Creative Commons Attribution License, which permits unrestricted use, distribution, and reproduction in any medium, provided the original work is properly cited.

\begin{abstract}
This is an inquiry that seeks to understand the meaning of experiencing a spinal cord injury for hospitalized Brazilian and Portuguese patients. A quailtative study was achieved in two care services to spinal cord injury in Fortaleza-Brazil and Lisboa-Portugal. The subjects were 30 patients with complete spinal cord injury. The findings were obtained through a semi-structured interview, which took place at different times and it was used the following guiding question: What does it mean for you to experience a spinal cord injury? The data were organized by Bardin technique and analysis based on the assumptions of the theory of Jean Watson's care. The speeches of the patients show a diversity of meanings such as: to lose the freedom of going and coming, sexuality and to become dependent on others. It is concluded that this situation of loss overbalances the person's existence, which is expressed by feelings of sadness, grief, discontent, isolation, anxiety, crying, pain and emotional suffering. These feelings were expressed by the two groups despite being from different cultures. The research enabled the description of multiple dimensions of the meaning of spinal cord injury. It fills the theoretical gap, not yet sufficiently addressed to the practice of caring people with spinal cord injury.
\end{abstract}

Keywords: Spinal Cord Injury; Comprehensive Analysis; Jean Watson's Theory

\section{INTRODUCTION}

Spinal cord injury is the term used to refer to any type of injury that happens in the neural elements located in the spinal canal. The damage in the spinal prevents the passage of voluntary impulses of the brain to the muscles and the skin sensitivities until the brain [1-3]. This disabling neurological syndrome is characterized by an aggression to the spinal cord causing its partial or total interruption and can cause neurological damage and neurovegetative disorders below the level of injury [4-6]. It is therefore a complex clinical condition, since it is considered one of the major causes of severe consequences in people affected. Few illnesses or injuries have the potential to produce such devastating effects in life or quality of life as the injury of the spine [7-9].

Data from the World Health Organization [10] indicate that $10 \%$ of the world population is composed by people with any kind of disability and from this percentage $20 \%$ have some kind of physical disability, however, not specified in this statistic the percentage of people suffering from spinal cord injury.

This chronic condition has been studied in more diverse facets, as shown in national and foreign literature concerning this subject [11-21]. Nonetheless there is still a gap in literature concerning the studies on understanding the meaning of experiencing a spine cord injury. This raises the need of an understanding about this act. It is vital to develop studies aiming to reveal new practical dimensions of caring and care for people with a spinal cord as well as to deepen the ones emerging. So, a great challenge for the profession is the production of knowl- 
edge that can bring benefits to others.

By this way, Watson [22] calls the nursing professionals to put an end in the old commitments concerning the technical procedures and help to clarify the nature of the profession's contribution to humanity towards the preservation of people and human care.

Studies of this nature establish a great contribution to the learning of neurological Nursing and serve as a source of knowledge but there is still a gap in respect to studies that have as the basic care of people with spinal cord injury (SCI), under the perspective of Watson's transpersonal caring theory [23], as the case here studied.

So, the shared experiences over the years, patients with spinal trauma injury, allied to what is exposed here, led us to study the meaning of spinal cord injury on the patients’ perspective.

\section{METHODOLOGICAL APPROACH}

\subsection{Subjects and Survey Methods}

A field study with a qualitative approach involving 30 patients of both sexes, 18 Brazilian and 12 Portuguese hospitalized in two hospital specialized in attending spinal cord injury in the cities of Fortaleza-Brazil and Lisbon-Portugal. Some criteria were taken in order to select the subjects. First, to be injured spinal cord trauma and to have been informed on the inability to walk. Second, to be aware about the irreversibility of spinal cord injury. This fact is so important since the person affected will answer questions based on certainties and not in probabilities.

The findings were obtained through a semi-structured interview and the question was: What does it mean for you to experience a spinal cord injury? This happened in different times as soon as the patients had been informed about the aims, methods of data collection of the study and a permission of using a recorder was asked. Then the subjects signed the informed consent form. The interviews were conducted in an atmosphere of cooperation without detachment or dispersal of matter that would break or stop the thought or speech of the interviewee. To ensure these aspects it was sought, wherever possible, environments that could provide privacy, comfort and freedom. Thus the existing leisure plaza in hospitals was chosen as it is a good opportunity for the patients to ride in a wheel chair. The duration of the interviews ranged from 50 to 90 minutes sand were conducted by the major author of this study.

\subsection{Data Analysis}

To record the data, files were organized to keep the interviews and field diaries for each patient. The data acquired were organized according to the method of Content Analysis, proposed by Bardin [24]. This technique was chosen because it consists of a method of unquestionable use in the investigations which involve evaluations and interpretations of data based on textual elements of discourse. Bardin [24] points out three basic phases to work with content analysis: Pre-analysis, Exploration of the material and Treatment of results through inferences and interpretations. In this study, the operational steps to organize the data covered the following stages: 1) Pre-analysis of the content of the transcribed interviews with the reading of information obtained, in order to clarify the content; 2) At this phase, exploration of the material, the data were coded from the units of registration; and 3) Treatment of results, the inference and the interpretation from the category achieved. The categorization aimed to provide a simplif ied representation of the raw data, characterized by the relevance of the material mode of analysis reflected from the intentions of the study. We opted for the semantic categorization, that is, through the study of linguistic units, so that the main material of the content analysis was the meanings assigned to live with a spinal cord injury. Revealing four thematic categories: loss of freedom to come and go, sexuality, faith, hope and meaning in life. The results were analyzed on the view of the theoretical framework of Watson and the existing literature.

\subsection{Ethical Aspects}

The ethical aspects of the research were respected according to the requirements established in Resolution 196/96 of the National Health Council, Brazil [25] in special about the preservation of the fundamental bioethical principles concerning respect, beneficence and justice for the individual and therefore those people involved were informed about the preservation of anonymity at the time of publication of the study of the research project and its approval by the Ethics Committee in the research of UFC/Brazil and hospital of Lisbon/Portugal.

\section{RESULTS AND DISCUSSION}

The sample is characterized for being predominantly male sex, only three patients of female sex, age ranging from 19 to 41 years, single and mean age 30 years.

Concerning education most of them had elementary and high school education and only two had superior education.

With respect to career or occupation, there is a diversity of professions. The family income ranged from one to six minimum salary and six patients were unemployed.

Regarding the mechanism of trauma, there has been a diversification of causes. Among these people stand out victimized by aggression of projectile of firearm, automobile accident, for tree falls and other mechanisms as 
wall collapsing and direct trauma. As to the level of bone injury it can be seen that the vertebral segment most affected was the thoracic spine. The period of hospitalization ranged from 12 to 58 days, with an average of 31 days of hospitalization for Brazilian patients and from 10 to 15 days for Portuguese patients. To live with a spinal cord injury means a loss filled up with a mixture of feelings (Figure 1).

The patients studied say that, with a spinal cord injury they loss the freedom to come and go, sexuality, faith hope and the meaning of life. It is therefore to experience a complex process of transformation of life permeated by different feelings. This condition of loss creates a disharmony in the person's life which is expressed by feelings of sadness, impotence, despair, social isolation, distress, pain and emotional suffering. This heartbreak chages the sense of the self and the questioning emerges I am not the same to what I was.

The fundamental points in Watson transpersonal model [23] are loss and care. The word "loss" is originnated from latim and has as etymological meaning "be deprived of", "cease". Concerning the studied theory, the loss creates a disharmony in the following spheres of the person: mind, body and spirit and because of this it demands care that takes into account the emotional and subjective world of the person. So, facing this condition of experiencing a spinal cord injury the patients interviewed, still plagued with the losses, experience feelings of sadness and distress, say they are depressed, have a tendency to isolation and sometimes worried they lose interest in activities they once played.

The loss is a painful blow to the human spirit. When caring for people who have suffered, the nurse also experiences her/his own feelings and has her/his personal world of meanings to explore, allow his/her own life, feelings, experiences and perceptions and accepts these feelings as part of the change and way as a human being.

About this matter, it is understood that losing part of

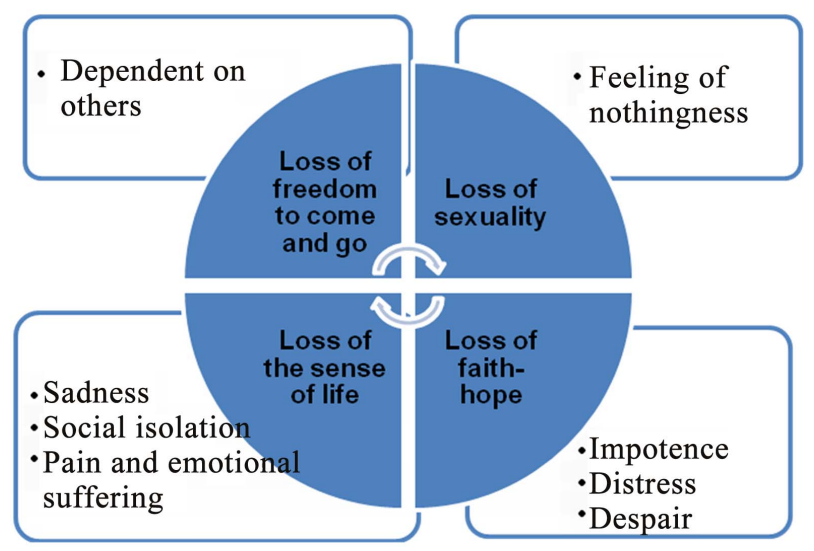

Figure 1. Sentiments expressed by spinal cord injury patient. Fortaleza-Ceará-Brasil, 2003. yourself can be even more difficult than that of a loved one.

The losses modify the person and the sequence of his/her life. Farther on, the losses shows that somebody who loses can even come to be happy again however no longer as he/she was in the past. This is quite evident in the speech of the patients.

"I think it's the worst possible, it is very complicated. I was athlete, practiced karate, my life is now in a wheelchair, that's terrible."

"I liked that I got back to walking... (grinned while saying this), I'm playing, because I know I will not walk anymore, it is a great loss in my life, I think I lost my freedom, now depend entirely on others."

"... It's weird because a few days ago I was doing my normal life, I'm mechanic, ride my bike, I bike, have a car, the beach and now I know that some things will be more difficult to overcome."

"But basically the only thing for me, the only thing that marks a difference that will depend on a wheelchair to be able to walk."

Okay, I feel sad and have to prove that I'm strong and I have to do everything possible to accept that I can spend the rest of my life in a wheelchair, do not know whether to be watching.

The patient, when expressing his/her feelings about the new living condition, spinal cord injury, alert the nurse to the enhancement of his/her existential dimension as paraplegic person. In this sense, Watson [23] shows that the nurse can join a transpersonal care process, comforting, listening and allowing free expression of feelings based on personal standards culturally relevant. This new way of caring, offered by Watson suggests that the nurse should allow the person ,in case, with a spinal cord injury, to face his/her internal fears as anger, sadness, pain and sorrow.

From the viewpoint of science, the patient expects the cure for his/her paraplegia, however, from science it will not come for a while. In this respect the relationship between faith and reason begin manifesting through doubts and uncertainties. It is therefore up to these people search in a superior force comfort for this time of grief. At this time, the nurse can help them to develop coping mechanisms to understand that even though paraplegics they can have quality of life, despite the spinal cord injury [26,27].

The disease situations in general, as well as losses, often make people turn to God. There are countless situations in which the despair due to disease and loss is a start to the restoration of faith [28]. This was perceived when they were asked how they felt about not being able to walk. They introduced the faith and hope, as starting points in aspiration for the cure, or at least acceptance and or conformation. 
Note that, for these patients, God is the source of faith and hope and is in Him that are deposited all the certainties of healing and conformation. So, they express their thinking as follows:

"I just believe in life, that thanks God, I'll be good If God wants, I'll walk";

"If He wants I'll walk again, but only a miracle";

"My hope is that God will listen to my prayers and heal me"; "If you do not have faith, the things get very complicated"; "One must have much faith in God, believing that one day sooner or later, again recover, be as it was before, if God wishes";

"There are those who claim to be conformed";

"With faith in God, we win it all";

"If I cannot be well, walk again, that $\mathrm{HE}$ at least give me conformation";

"I’m resigned, I can do nothing”.

Other patients consider the suffering a punishment as well and wonder:

"Why did God do this for me?”;

"Only a miracle, is there a miracle?”;

"I did not pray, now, everyday I ask God that grace";

"If God cures me, I'll change my way of living completely."

In his theoretical model, Watson [29] places great emphasis on spiritual and therefore recommends that the concerns about the care can be directed to the spiritual and existential dimensions of the person. In this sense suggests the installation of faith and hope that, in his view is essential as to care as to the healing. This factor allows the acceptance of alternative forms of care, among which the meditation and the healing by the thought. So, when science has nothing to offer to the person, the nurse can use faith and hope to provide to provide a sense of well being through the beliefs and values significant for both.

It is interesting to note that the patients identify God as their support system, that is, for these people, the faith in HIM gives a deeper dimension than the force coming from people. In general, the religious beliefs provide strength and internal quietness. It is pertinent to note that, even though they are cleared by the doctor about the irreversibility of paraplegia they demonstrate not to accept this fact. Patients show that it is faith in divine providence that make them struggle to overcome the problem of paraplegia or even conform to this new condition of life.

On this subject Glynn [30] refers to a stud on religious belief as a condition for happiness and psychological well-being in general. The result reached was that those who profess a faith in a more solid way reported greater happiness in all spheres of life. The ones who said to be "very happy" expressed like this: "My religious faith is the most important influence in life.” Benson [28] in a paper titled "Epidemiological evidence of benefits of religious belief and commitment” says: I found that faith quiets the mind as no other form of belief. He argues that affirmative beliefs and hope are quite therapeutic, and that, in particular, faith in God has many positive effects on health, as it calms the mind, increases the hope and may even raise the efficacy of treatment.

Nurses and patients look for conceptions about faith and hope with the desire to understand the meaning of experiencing a spinal cord injury, and know that the model of transpersonal care involves a strong score on the values of people involved. The difficulties patients have to express themselves about the issues are notorious.

For Watson [22] the goals of care model are associated with the growth mental spiritual of the self and the others. Both the nurses and patient find meaning in their own existence and experience, discovering the internal power potentiating transcendence understood as what as beyond experience that is external to the world of experience. Man is a complex human being formed of mind, body and soul, which explains his transcendental perceptions. However, there are few people who regard the transcendence due to their limitations in knowledge and in the practice of the sciences that explain the creation of the world, the man and of everything in it.

The scholars Rocha and Fleck [31] showed that religiosity tends to increase during the negative events in one's life such as the disease. They point out that religiosity, spirituality and personal beliefs are sources of protection for delinquent behavior, abuse of harmful drugs, psychological distress and suicide. About life satisfaction and spirituality among people with chronic spinal cord injury, Brilhart study [32] shows that there is significant positive correlation between life satisfaction and psychological and spiritual factors according to the instrument used in the research.

In the structure of Watson transpersonal model [23] it is suggested to the nurses the incorporation of existential and phenomenological forces, as a way to understand these people, from the point of view of how things are presented to them from its existential structure. This aspect helps the nurse to understand the meaning the person gives to his/her life or can help the person to find meaning in the hard events of life, contributing also to find strength or courage to face life or death.

We observe sharp divergence of thought between Brazilian and Portuguese patients about faith and hope. Brazilian patients emphasized more aspects of the issues facing knowledge of religious belief and religion while, manifested by impotence, distress and despair the Portuguese showed faith as the meaning of life, translated as sadness, social isolation, pain and emotional suffering. In these respects there was no difference between the sexes. 
However there was no difference between the sexes. Faith can be understood from the religious point of view as the attitude of a true believer that connects to God by a voluntary act, from a witness of supernatural origin. The belief would be the attitude through which we affirm with some degree of probability or certainty, the reality or truth of something, though we cannot prove them rationally or objectively [33].

The author mentioned above [33] says that the spiritual dimension can be the engine of the person with spinal cord injury helping to manage the consequences of the injury, preserving life goals to fulfill and valuing life. Thus, studies involving aspects of religiosity and spirituality and personal beliefs deserve, as all and any other object of research, the systematic and rigorous application of the scientific method to validate them, regardless preconceived attitudes for or against any results.

In the context of living with a spinal cord injury, our view is that this aspect needs to be widely discussed by the nurse. So in this direction, Caldeira, Branco, Vieira [34] report on the importance of the spiritual dimension in the processes of health/disease, since this is recognized by national and international nursing associations and demonstrated by scientific evidence. However this dimension remains forgotten in the nursing care. Hence, it is important the nurse incorporates a new way of thinking about emotional life for her and the patient as well, through the reassertion of moral and spiritual dimensions of human life, as suggested by Watson [22].

Continuing the issue of the meaning of spinal cord injury, it is revealed that the need for sexuality is affected and this produces a strong worry in the patient life. To be paraplegic is to become a useless man. It means not to be a man any more. This fact is spoken in their talks when positioned themselves as follows:

"How will I live with my wife, things of man and woman have worried me";

"It's a very difficult thing to talk, I'm a useless man from the waist down";

"I'm worried about my legs that I'm not moving, my girlfriend travelled and never came back";

"My concern is not to be able to have a relationship as in the past, to have more sons, How is it going to be my relationship with a woman?";

"I feel myself disabled, I am no longer a man, even my girlfriend does not want me anymore";

"It worries me questions about my self-image, sexuality and fertility, is still going to be a mother, will I get pregnant?"

Observe, that in daily nursing care to the person with a spinal cord injury, the importance of sexual function in these people's lives has been placed in a secondary plan. Some reasons are listed which seem to explain this attitude, that is, nursing care do not pay great attention to the sexual problems of paraplegic and quadriplegic mainly the reason related to the belief that sexuality is for healthy people and that the individual sexual life is not a vital area for recovery.

The fact is that, the person with a spinal cord injury has difficulty in identifying with the human figure and integration with the body design, that is, the person feels incomplete and does not get to integrate the physical parts and forms in a new body image. Thus, after injury, a conflict of acceptance and adaptation to the new circumstances arises and after this a new body image is established. The paraplegic needs to know the limitations and modifications, including learn how to handle the equipments that is used (wheelchair, urine collector) for a new experience of his own body, and must be able to explain this situation to the others because feelings of shame and fear are experienced besides the concern that the deformity may be the cause of social and sexual rejection, commonalities among patients Brazilians and Portuguese in both men and women. Add to that the problems mentioned on fertility in both sexes.

Cavalcante [35] thinks that this experience of feeling sexual impotence, especially in paraplegic man creates serious adjustment problems, makes him feel inferior and the feeling of being betrayed continuously, since the image he has of his body is defective and useless. Faced with this problem, it is the nurse who seeks to know and guide paraplegics also about sexual problems consequent to the spinal cord injury, demystify what exists on paraplegia and sexuality, as well as discuss about the options to give and receive sexual pleasure [12,36].

One way to achieve this argumentation is to incorporate, in practice, the care factor of gratification of human needs. In this sense, Watson [18] established a hierarchy for human and sexual needs be included as lower-order or psychophysical needs also called functional needs. Thus it is clear that the model of care/caring pointed out by the scholar is concerned with this aspect of the life of the person who suffers a loss.

\section{IMPLICATIONS FOR RESEARCH AND NEUROLOGICAL NURSING}

This is an attempt to fill the gap theory, not yet sufficiently addressed to the practice of neurological nursing, especially for people with spinal cord injury, since there are few studies that explore the living and experiences that affects the person with this clinical condition. The reports presented here can support future research exploring other meanings of living a spinal cord injury. This may be especially important when it comes to new ways of caring which needed emotional and relational challenges from the nurses are.

Understanding the spinal cord injury of inpatients 
grounded in the model of transpersonal care can be considered as a way of extending the principle to practice and whereas this model offers opportunity for growth and autonomy of nursing in the hospital setting. It is therefore, a moment of discovery, pursuit of inter-subjectivity, because at the time the nurses interact with patients learn to recognize them as human beings and so reflect on their ways of living being and acting together, understand the meaning of caring for people with spinal cord injury through dialogues.

\section{CONCLUSIONS}

This qualitative study aimed to understand the meaning of experiencing a spinal cord injury for Brazilian and Portuguese patients hospitalized, supported by the assumptions of the model of Watson transpersonal care, allowed the description of multiple dimensions of understanding the meaning of the object studied.

For the patients, the meaning of experiencing a spinal cord injury is permeated by feelings of loss in all walks of life and changes in bodily, emotional and spiritual schema. The installation of dependence condition is a feeling that may mean impotence and hopelessness. The need of assuming the physical disability produces another meaning, that is, the constraint of becoming a "burden" and cause trouble to the family.

The theory of Human Care is based on the belief that when a nurse and a patient are together, they create the possibility of finding a meaning within the experience they experienced. As Watson's theory explains itself, the art of nursing care begins when the nurse, with the goal of helping the other through a sense of care and attention, expresses this feeling with clear attitudes. She goes farther remembering that this notion of inter-subjective care/caring opposes to the models "care for" and "caring of” people living with a spinal cord injury.

\section{ACKNOWLEDGEMENTS}

This article is part of the research carried out under the Graduate Program in Nursing, Department of Nursing UFC and hospitals Institute Dr. Jose Frota, Fortaleza-Ceará-Brazil and Hospital São Jose Lisbon/Portugal for the opportunity of access to its facilities and patients who agreed to participate in this research.

\section{REFERENCES}

[1] American Spinal Injury Association (2011) International standards for neurological classification of spinal cord injury. American Spinal Injury Association, Atlanta. http://www.asia-spinalinjury.org/publications/59544 sc Exam Sheet r4.pdf

[2] Silva, G., Schoeller, D., Gelbcke, F., Carvalho, Z. and Silva, E. (2012) Functional assessment of people with spinal cord injury: Use of the functional independence
measure-FIM. Texto \& Contexto Enfermagem, 21, 929936. doi:10.1590/S0104-07072012000400025

[3] Andrade, M. and Gonçalves, S. (2007) Traumatic spinal cord injury-Neurological and functional recovery. Acta Médica Portuguesa, 20, 401-406.

[4] Riberto, M., Pinto, P., Sakamoto, H. and Battistella, L. (2005) Functional independence of patients with spinal cord injury. Acta Fisiátrica, 12, 61-66.

http://www.actafisiatrica.org.br/

[5] Carvalho, Z. (2010) General overview of spinal injury. In: Carvalho, Z., Darder, J., Mulet, F., Nuñez, A. and Mulet, C., Eds., Spinal cord injury: Care booklet, Nursing Council of Valencia, Alicante, 24-25.

[6] Sarah Network of Rehabilitation Hospitals (2008) Information on diseases treated: Spinal cord injury. Brasília. http://www.sarah.br/

[7] Bampi, L., Guilhem, D. and Lima, D. (2008) Quality of life in persons with spinal cord injury: A study with WHOQOL-bref. Revista Brasileira de Epidemiologia, 11, 67-77. doi:10.1590/S1415-790X2008000100006

[8] Brunozi, E., Silva, A., Gonçalves, L. and Veronezi, R. (2011) Quality of life in traumatic spinal cord injury. Revista Neurociências, 19, 139-144.

[9] Vall, J., Braga, V. and Almeida, P. (2006) Study of quality of life in people with spinal cord injury. Arquivos de Neuro-Psiquiatria, 64, 451-455. doi:10.1590/S0004-282X2006000300019

[10] World Health Organization (2011) The WHO family of international classifications. http://www.who.int/classifications/en/index.html.

[11] Berto, C. and Barreto, D. (2011) People with spinal cord injury: The biopsychosocial changes and expectations experienced. Unoesc \& Ciência-ACHS, 2, 174-183.

[12] Brito, M., Bachion, M. and Souza, T. (2008) Nursing diagnoses that most occur in people with spinal cord injury in the context of outpatient care by model-based approach of Orem. Revista Eletrônica de Enfermagem, 10, 13-28.

[13] Carvalho, Z. and Damasceno, M. (2003) Aplicación de la del careful transpersonal theory en paraplegics hospitalized patients: Experience repor. Ciencia y Enfermería, 9, 77-94.

[14] Rabeh, S. and Caliri, M. (2010) Functional capacity in individuals with spinal cord injury. Acta Paulista de Enfermagem, 23, 321-327. doi:10.1590/S0103-21002010000300002

[15] Sartori, J., Neuvald, M., Bastos, V., et al. (2009) Physical rehabilitation in traumatic spinal cord: A case report. Revista Neurociências, 17, 364-370.

[16] Coura, A., França, I., Enders, B., et al. (2012) Disability and associations with sociodemographic characteristics in adults with spinal cord injury. Revista Latino-Americana de Enfermagem, 20, 84-92. doi:10.1590/S0104-11692012000100012

[17] Chagas, A., Mindêllo, M., Figueredo, J., Carvalho, Z., et al. (2011) Lesão medular: Produções de enfermagem na pós-graduação brasileira. ReTEP—Revista Tendência da 
Enfermagem Profissional, 3, 399-405.

[18] Venturini, D., Decesaro, D. and Marcon, S. (S/D) Spinal cord injury: Productions in nursing graduate Brazilian. Revista Gaúcha de Enfermagem, 27, 219-229. http://seer.ufrgs.br/RevistaGauchadeEnfermagem/article/ view/4600/2520

[19] Costa, V., Melo, M., Garanhani, M. and Fujisawa, D. (2010) Social representations of the wheelchair for people with spinal cord injury. Revista Latino-Americana de Enfermagem, 18, 755-762. http://www.scielo.br/pdf/rlae/v18n4/14.pdf

[20] Studart, R., Carvalho, Z., Mesquita, E., et al. (2011) The Waterlow scale applied in people with spinal cord injury. Avances en Enfermería, 29, 247-254.

[21] Paz, L., Rodríguez, M., Garriga Cossio, J. and Quinteiro, I. (2005) Triggering of enfermería y aplicación del Barthel Index patients injured spinal cord injury clinical en la del CIREN. http://www.mednet.cl/link.cgi/Medwave/Enfermeria/200 5/noviembre/2786

[22] Watson, J. (1979) Nursing: The philosophy and science of caring. Little Brown and Company, Boston.

[23] Watson, J. (1985) Nursing: Human science and human care, a theory of nursing. National League for Nursing, New York.

[24] Bardin, L. (2009) Content analysis. Edições 70 Ltda, Lisboa.

[25] Brasil (1996) Ministério da Saúde. Conselho Nacional de Saúde. Comissão Nacional de Ética em pesquisaCONEP. Resolução n ${ }^{\circ}$ 196/96: Sobre pesquisa envolvendo seres humanos. $24 \mathrm{pp}$.

[26] Scramin, A. and Machado, W. (2006) Caring for people with tetraplegia in home environment: Nursing interventions in long-term dependence. Escola Anna Nery Revista de Enfermagem, 10, 501-508. doi:10.1590/S1414-81452006000300020

[27] Murta, S. and Guimarães, S. (2007) Coping with spinal cord injury. Estudos de Psicologia (Natal), 12, 57-63.
http://www.scielo.br/scielo.php?pid=S1413-294X200700 0100007\&script=sci arttext

[28] Benson, H. (1996) Timeless healing. Sinon e Schuster, New York.

[29] Watson, J. (1988) Nursing: Human science and human care, a theory of nursing. National League for Nursing, New York.

[30] Glynn, P. (1997) God the evidence: The reconciliation of faith a reason in a post secular world. Prima Publishing, New York.

[31] Rocha, N. and Fleck, M. (2011) Evaluation of quality of life and the importance given to spirituality/religion/personal beliefs (SRPB) in adults with and without chronic health problems. Revista de Psiquiatria Clínica, 38, 1923.

[32] Brillhart, B. (2005) Astudy of spirituality and life satisfaction among persons with spinal cord injury. Rehabilitation Nursing, 30, 31-34. doi:10.1002/j.2048-7940.2005.tb00353.x

[33] Amaral, M. (2009) Finding a new sense of life: A study about the adaptation after spinal cord injury. Revista da Escola de Enfermagem, 43, 573-580. doi:10.1590/S0080-62342009000300011

[34] Caldeira, S., Branco, Z. and Vieira, M. (2011) Spirituality in nursing care: A review of scientific publications in Portugal. Revista de Enfermagem Referência, 5, 145-152. doi:10.12707/RIII1133

[35] Cavalcante, K., Carvalho, Z., Barbosa, I. and Studart, R. (2007) Alterations in the fertility lived deeply by people with spinal cord injury: A qualitative research. Online Brazilian Journal of Nursing, 6. http://www.objnursing.uff.br/index.php/nursing/article/vi ew/j

[36] Cavalcante, K., Carvalho, Z., Barbosa, I. and Rolim, G. (2008) Experience of the sexuality by people with spinal cord injury. Revista da Rede de Enfermagem do Nordeste, 9, 27-35. 